\title{
Saúde e bem-estar nos ODS: \\ Problematizando os conceitos de saúde e doença a partir do diálogo entre saberes
}

\author{
Andréia Gimenes Amaro ${ }^{1}$ \\ Viviane Kraieski de Assunção ${ }^{2}$ \\ Universidade do Extremo Sul Catarinense
}

Resumo: Saúde e bem-estar são questões prioritárias nos documentos que se propõem a orientar as nações rumo ao desenvolvimento sustentável. Contempladas no objetivo 3 dos Objetivos de Desenvolvimento Sustentável (ODS), propostos pela Organização das Nações Unidas, estas questões refletem o conhecimento biomédico e atendem aos interesses do modelo de desenvolvimento capitalista. Este artigo problematiza as concepções que orientam as estratégias que visam o desenvolvimento sustentável e o modelo de desenvolvimento com o qual estão comprometidas. Por fim, aponta a intermedicalidade como um caminho possível na promoção efetiva da saúde e do bem-estar das pessoas.

Palavras-chave: saúde; bem-estar; desenvolvimento; desenvolvimento sustentável; interculturalidade. 


\title{
Health and well-being in the SDG: problematizing health and disease concepts from the dialogue between knowledges
}

\begin{abstract}
Health and well-being are priority issues in the documents that aim to guide nations towards sustainable development. Contemplated in goal 3 of the Sustainable Development Goals (SDG), proposed by the United Nations, these questions reflect biomedical knowledge and meet the interests of the capitalist development model. This article reflects on the concepts that guide the strategies aimed at sustainable development, and the development model to which they are committed. Finally, it points to intermedicality as a possible way to effectively promote people's health and well-being.
\end{abstract}

Keywords: health; well-being; development; sustainable development; interculturality.

\section{Salud y bienestar en ODS: Problematizando los conceptos de salud y enfermedad a partir del diálogo entre saberes}

\begin{abstract}
Resumen: La salud y el bienestar son temas prioritarios en los documentos que tienen como objetivo guiar a las naciones hacia el desarrollo sostenible. Contempladas en el objetivo 3 de los Objetivos de Desarrollo Sostenible (ODS), propuesto por las Naciones Unidas, estas preguntas reflejan el conocimiento biomédico y satisfacen los intereses del modelo de desarrollo capitalista. Este artículo reflexiona sobre los conceptos que guían las estrategias dirigidas al desarrollo sostenible y el modelo de desarrollo al que están comprometidos. Finalmente, señala la intermedicalidad como una forma posible de promover efectivamente la salud y el bienestar de las personas.
\end{abstract}

Palabras clave: salud; bienestar; desarrollo; desarrollo sostenible; interculturalidad. 
$\mathrm{D}$ efinida pela Organização Mundial da Saúde (OMS) como "um estado de completo bem-estar físico, mental e social e não somente ausência de afecções e enfermidades”, a concepção de saúde, assim como a de doença, vem sendo modificada ao longo da história e não constitui um consenso. Permeadas por aspectos intrinsecamente relacionados a processos históricos, culturais, políticos, econômicos, técnicos e científicos, as concepções de saúde e doença agregam, sobretudo, interesses na manutenção do poder e da influência de classes e sistemas dominantes em âmbito global.

Essa percepção se evidencia ao analisarmos de forma mais atenta o Objetivo 3, que trata da saúde e bem-estar nos Objetivos de Desenvolvimento Sustentável (ODS). Estes apresentam um plano de ação composto por 17 objetivos e 169 metas, que se desdobram em um conjunto de programas, ações e diretrizes que orientarão os trabalhos das Nações Unidas e de seus países membros rumo ao desenvolvimento sustentável pela próxima década. Argumentamos neste artigo que as metas e ações propostas para o alcance do objetivo refletem uma visão unilateral e reducionista incapaz de contemplar a multiplicidade das dimensões que integram os diferentes sujeitos e realidades vividas. Aliada a isso, a tríade inovação, tecnologia e mercado nos leva a refletir sobre o enfoque e a pertinência de seu objetivo final: o desenvolvimento.

Por meio de pesquisa bibliográfica e análise documental, discutimos neste artigo, num primeiro momento, as bases que orientaram a elaboração dos ODS e as concepções de saúde e doença sobre as quais se fundam as estratégias e ações contidas no objetivo 3 deste mesmo documento. Posteriormente, apontamos alguns dos preceitos contidos nos documentos que corroboram uma noção de desenvolvimento vinculada e comprometida mais com as formas de conhecimento hegemônicas e com os interesses mercadológicos do que efetivamente com a saúde e o bem-estar das pessoas de forma mais abrangente. Por fim, trazemos os conceitos de interculturalidade e diálogos de saberes como alternativas para contemplar a pluralidade de conhecimentos e técnicas nas estratégias que visam atingir um desenvolvimento sustentável.

\section{Concepções sobre saúde e doença: do "mágico-religioso" ao modelo biomédico}

A hegemonia das concepções de saúde e doença pautadas no modelo biomédico está atrelada ao processo histórico de transformação da ciência em única forma de conhecimento válido. O controle das instituições políticas sobre o exercício da medicina e a supremacia da categoria médica sobre os populares foram instituídos na Revolução Francesa com o objetivo de proteger e oferecer assistência à sociedade civil através do controle (IGREJA, 2016: 30). Este processo, que se perpetua até os dias atuais, foi acompanhado de decorrentes confrontos entre 
argumentos que privilegiavam formas de conhecimento alinhadas ao sistema dominante e os que priorizavam outras formas de conhecimento voltadas à busca pela felicidade e o equilíbrio, conforme destacam Santos, Meneses e Nunes (2005: 21):

A vitória do primeiro argumento explicou-se em parte pela crescente ascendência do capitalismo e das potencialidades de transformação social sem precedentes que trazia no seu bojo. A vitória teve de ser tão completa quanto às rupturas que se pretendiam com a sociedade anterior. E, para ser completa, teve de envolver a transformação dos critérios de validade do conhecimento em critérios de cientificidade do conhecimento. A partir de então a ciência moderna conquistou o privilégio de definir não só o que é ciência, mas, muito mais do que isso, o que é conhecimento válido.

Essa transformação epistemológica consolidada no século XIX, que intitula a ciência como única via legítima de acesso ao conhecimento, nega a diversidade e relega os conhecimentos "tradicionais" ou alternativos, que até então orientavam as práticas de determinados grupos sociais, à marginalidade ou, em casos mais extremos, promove um epistemicídio (SANTOS, MENESES, NUNES, 2005).

Em diálogo com Edgar Morin, promovido pela Universidade de Brasília (UnB), em 1999, o líder indígena Marcos Terena expressa o sentimento do seu povo quando destaca que "não ser moderno, não ser desenvolvido, não significa ser culturalmente pobre" e reafirma: "nós índios, nascemos com uma sabedoria, um conhecimento, também religioso e espiritual, e quando chegou a civilização nada disso teve valor ou sentido [...] o homem branco não sabia compreender a linguagem indígena" (MORIN, 2010: 23).

A ideia de raça forjada pelos colonizadores fundamentava desigualdades e justificava opressões na distinção da estrutura biológica e genética dos indivíduos. Com isso, relegava povos, principalmente indígenas e negros, a uma situação de inferioridade e naturalizava as relações pautadas na dominação. A codificação das diferenças entre colonizadores e colonizados com base nos traços fenotípicos, como, por exemplo, a cor da pele, serviu como instrumento de categorização social da população que orientava os espaços a serem ocupados e os papéis sociais cabíveis a cada um, inferiorizando "suas descobertas mentais e culturais" (QUIJANO, 2005: 118).

Com base na lógica colonialista, os conhecimentos dos povos subjugados são tidos como crendices populares e seus rituais considerados manifestações de irracionalidade. Com isso, grandes possibilidades de compreensão e atuação no mundo são deslegitimadas. A Europa, referenciada como o grande centro difusor dos conhecimentos que compõem a história da humanidade, reprime os conhecimentos construídos no seio de sociedades de nações colonizadas, colocando-os em posição de subalternidade (CHAKRABARTY, 2000): "essa hegemonia da Europa ajudou a espalhar uma imagem invertida, na qual o conhecimento europeu é universal e os 'outros' são conhecimentos particulares” (MARTINS, 2014: 24).

À exceção do conhecimento científico, as demais formas de produção e transmissão de conhecimento foram relegadas ao obscurantismo e à obsolescência; tornaram-se artefatos de museu, apelidados de "tradicionais" (SANTOS, 2005: 30). Em decorrência deste processo, foram desconsiderados, no conceito de "conhecimentos tradicionais", a dinâmica e os processos de ressignificação decorrentes das vivências e dos desafios impostos por circunstâncias históricas e espaço-temporais (CUNHA, 2009).

Considerando esta perspectiva, cabe problematizar as concepções hegemônicas de saúde e doença. A diversidade de práticas relacionadas à saúde, segundo Batistella (2007: 28), "tem estreita relação com as formações sociais e econômicas, os significados atribuídos e o conhecimento disponível em cada época”. Cabe 
também ressaltar que estas diferentes concepções são produtos da história e existem sob um determinado contexto ambiental e cultural que está em permanente mudança devido às influências econômicas, filosóficas e religiosas. Por isso, há necessidade de cautela e critério ao comparar sistemas médicos de diferentes culturas (CAPRA, 1982: 117).

As concepções sobre saúde e doença modificaram-se ao longo de sua trajetória, dos conhecimentos chamados "mágico-religiosos", elaborados na Antiguidade, ao modelo biomédico, consolidado atualmente. É importante ressaltar que o termo "mágico-religioso" é também uma invenção da modernidade; uma maneira depreciativa de se referir a outras formas de conhecimento que não a científica.

Para a medicina "mágico-religiosa", as doenças estão relacionadas a transgressões individuais ou coletivas de códigos morais e/ou a influências espirituais. Nesse sentido, a cura depende de um "realinhamento", ou seja, de uma religação entre o humano e o sagrado, promovida por meio de rituais realizados por líderes espirituais (feiticeiros, sacerdotes, xamãs, dentre outros), devidamente autorizados e reconhecidos pelas comunidades em que estão inseridos (BARROS, 2002: 68).

Trazemos aqui como exemplo a cosmovisão dos Tenek, grupo étnico descendente de civilizações mesoamericanas, cuja medicina "tradicional" está diretamente relacionada com forças espirituais e é praticada por meio de rituais que buscam restabelecer o equilíbrio entre o homem e o cosmos em sua totalidade.

\begin{abstract}
las enfermedades no son entendidas como procesos químico biológicos, fisiológicos o de alteraciones orgánicas, que tengan manifestaciones en forma de síntomas de "malestar". La enfermedad es más bien comprendida en la dimensión hombre - naturaleza, hombre - medio ambiente, en donde la causal del trastorno es la pérdida del equilibrio entre las dos partes del binomio. Por su parte, la medicina, es comprendida como parte de las prácticas rituales que se destinan a establecer, y en su caso a restablecer ese equilibrio, propiciando nuevamente la armonía y el estado de "bienestar" tanto en las personas, como en las comunidades. (GÜEMES, 2012: 19)
\end{abstract}

Nos sistemas médicos africanos, desenvolvidos com base "na arqueologia e na epistemologia das religiões africanas", os sujeitos não se restringem a "um corpo que está perante nós, mas à personificação das relações do passado, presente e futuro entre vivos e mortos". Nesse sentido, "a origem de males e sofrimentos [...] é atribuída a rupturas nas relações entre os vivos, ou entre os vivos e os mortos ou o mundo espiritual" (XABA, 2005: 384).

No Brasil, essas medicinas, que permanecem vivas e latentes, remontam o período colonial protagonizadas pelos indígenas, na figura do pajé, e os negros escravizados que desempenhavam o papel dos curandeiros, dominando as práticas denominadas mágicas e o conhecimento da medicina natural. Nesse período, "chás, mezinhas, rezas, feitiços, benzeduras, procedimentos rituais, interdições variadas faziam parte das curas que eram - inutilmente, como se pode imaginar coibidas pela Inquisição" (SCLIAR, 2005: 16-17).

De acordo com Viotti (2012: 17), outros atores sociais destacaram-se nessa época, pelo cuidado com a saúde da colônia; os religiosos, comprometidos em "salvar almas", também se dedicavam ao cuidado com a saúde "tão fragilizada pela incidência de enfermidades até então desconhecidas por seus organismos". Para tanto, utilizavam-se da "farmacopeia indígena na cura de determinadas doenças", o que além de otimizar as terapêuticas dos missionários, "reduziu significativamente o caráter depreciativo atribuído às práticas indígenas quando, como se pode prever, esta não era utilizada pelos nativos, mas sim pelos religiosos" (VIOTTI, 2012: 17). 
Um dos grandes legados dos sistemas etnomédicos dos ameríndios e de outras culturas, além dos vastos conhecimentos relacionados às plantas e suas propriedades curativas, é a compreensão do indivíduo em sua integralidade, ou seja, "a partir do conjunto de relações sociais estabelecidas no interior de uma comunidade e de uma cosmogonia própria” (BATISTELLA, 2007: 29).

Contrastando com a percepção de saúde e doença das etnomedicinas, o modelo biomédico ou mecanicista, consolidado na atualidade como a única via legítima de acesso aos conhecimentos acerca das práticas médicas, compartilha dos preceitos da ciência moderna. De acordo com Menéndez (2005), o modelo biomédico possui como principais características:

biologismo, asociabilidad, ahistoricidad, aculturalismo, individualismo, eficacia pragmática, orientación curativa, relación médico/paciente asimétrica y subordinada, exclusión del saber del paciente, profesionalización formalizada, identificación ideológica con la racionalidad científica, salud/enfermedad como mercancía, tendencia a la medicalización de los problemas y a la escisión entre teoría y práctica. (MENENDÉZ, 2005: 12)

Compartilhando dessa perspectiva, Langdon (2010) observa que a ciência biomédica trabalha com unidades universais, descontextualizando as doenças do espaço e condições em que ocorrem, ignorando, dessa forma, "valores, subjetividades e especificidades culturais” (BECKER, 2009: 2). Cabe destacar que o privilégio da biomedicina sobre outras concepções e práticas médicas não se deve unicamente "por sua eficácia curativa, mas também como resultado da expansão da economia global de mercado" (FOLLÉR, 2004: 110).

No entanto, a crise da ciência moderna, analisada sob diferentes enfoques por diversos autores (CAPRA, 1982; MORIN, 1993; BAUMAN, 1998; BOFF, 2014), propiciou uma abertura epistêmica que trouxe à tona saberes e práticas plurais relegados à obscuridade pela imposição hegemônica do conhecimento instituído como legítimo pelo sistema capitalista. De acordo com Santos (2005: 52), esta abertura "tem vindo a permitir o reconhecimento da existência de sistemas de saberes plurais, alternativos à ciência moderna ou que com esta se articulam em novas configurações de conhecimentos”.

$\mathrm{Na}$ atenção à saúde, são justamente as limitações inerentes ao modelo biomédico, associadas ao reconhecimento de outras formas de ser, estar e atuar no mundo, que justificam a necessidade e respaldam o surgimento de outros modelos. A exemplo, no Brasil, podemos citar o programa Saúde da Família (SF), posteriormente denominado Estratégia Saúde da Família (ESF), que emergiu na década de 1990. Inspirado nas resoluções de Alma-Ata prescrevia "assistência integral e contínua às famílias e comunidades, em seu espaço social, entendidas e atendidas a partir do local onde vivem, trabalham e se relacionam" (FERTONANI et al., 2015: 1873). Ainda incipiente, esse modelo propõe uma visão ampliada dos processos saúde/doença, partindo da compreensão da integralidade e capacidade de autogestão dos sujeitos, contrapondo, portanto, o caráter assistencialista que fundamenta as práticas do modelo biomédico.

\section{Objetivos de Desenvolvimento Sustentável: considerações sobre o objetivo 3}

A Agenda 2030 e os Objetivos de Desenvolvimento Sustentável surgem a partir de um diagnóstico dos avanços e das estagnações resultantes dos Objetivos de 
Desenvolvimento do Milênio (ODM), lançados em 2000, pela ONU. Esse diagnóstico, registrado em um documento intitulado "Relatório dos Objetivos de Desenvolvimento do Milênio", contém dados das mais de 28 agências das Nações Unidas e, embora ressalte os avanços alcançados nos 15 anos de vigência do plano, evidencia que "os progressos foram irregulares entre as regiões e países, deixando lacunas significativas". Acrescenta, ainda, que "milhões de pessoas estão a ser deixadas para trás, em particular as mais pobres e desfavorecidas, devido ao seu sexo, idade, deficiência, etnia ou localização geográfica".

Em decorrência disso, são lançados os ODS, por meio dos quais os países signatários "comprometeram-se a tomar medidas ousadas e transformadoras [...] para pôr o mundo em um caminho sustentável e robusto", sem deixar ninguém para trás (NAÇÕES UNIDAS, 2015).

O plano de ação composto por 17 objetivos e 169 metas propõe, durante a sua vigência, estimular áreas de importância crucial para a humanidade e para o planeta de maneira a incorporar, de forma equilibrada, as três dimensões do desenvolvimento sustentável: a econômica, a social e a ambiental.

O documento inicia com uma declaração dos Chefes de Estado e de Altos Representantes ressaltando a visão, os princípios e compromissos compartilhados entre países. Centrado nas pessoas, reconhece a dignidade da pessoa humana como fundamental, enfatizando o empenho em ações que visem o combate às desigualdades, a erradicação da fome, doença e da pobreza e a proteção dos direitos humanos, antevendo um mundo "onde toda a vida pode prosperar" (NAÇÕES UNIDAS, 2015).

No decorrer, o documento apresenta um panorama geral do mundo atual, destacando, dentre os principais desafios enfrentados, a pobreza, as desigualdades de oportunidades, riqueza, poder, e de gênero, a violência, a intolerância, a degradação ambiental e o esgotamento de recursos e as mudanças climáticas. No entanto, ressalta o grande progresso alcançado em diversas áreas, dentre as quais a medicina, por meio do acesso à educação, apostando no potencial "da informação e das tecnologias de comunicação e interconectividade global [...] para acelerar o progresso humano, para eliminar o hiato digital e desenvolver sociedades do conhecimento, tal como a inovação científica e tecnológica" (NAÇÕES UNIDAS, 2015).

Ao final das abordagens introdutórias, a frase: "É uma Agenda do povo, pelo povo e para o povo" pretende motivar o engajamento de todos e todas na consolidação dos ODS e, consequentemente, na construção de um mundo melhor.

Constituindo um dos grandes desafios da atualidade, a saúde recebe destaque no Objetivo 3 dos ODS buscando "Assegurar uma vida saudável e promover o bem-estar para todos, em todas as idades". Para tanto, este objetivo é composto pelas seguintes metas, das quais grifamos algumas:

\footnotetext{
3.1 até 2030, reduzir a taxa de mortalidade materna global para menos de 70 mortes por 100.000 nascidos vivos

3.2 até 2030, acabar com as mortes evitáveis de recém-nascidos e crianças menores de 5 anos, com todos os países objetivando reduzir a mortalidade neonatal para pelo menos até 12 por 1.000 nascidos vivos e a mortalidade de crianças menores de 5 anos para pelo menos até 25 por 1.000 nascidos vivos

3.3 até 2030, acabar com as epidemias de AIDS, tuberculose, malária e doenças tropicais negligenciadas, e combater a hepatite, doenças transmitidas pela água, e outras doenças 18 transmissíveis

3.4 até 2030, reduzir em um terço a mortalidade prematura por doenças não transmissíveis por meio de prevenção e tratamento, e promover a saúde mental e o bem-estar 3.5 reforçar a prevenção e o tratamento do abuso de substâncias, incluindo o abuso de drogas entorpecentes e uso nocivo do álcool
} 
3.6 até 2020, reduzir pela metade as mortes e os ferimentos globais por acidentes em estradas

3.7 até 2030, assegurar o acesso universal aos serviços de saúde sexual e reprodutiva, incluindo o planejamento familiar, informação e educação, bem como a integração da saúde reprodutiva em estratégias e programas nacionais

3.8 atingir a cobertura universal de saúde, incluindo a proteção do risco financeiro, o acesso a serviços de saúde essenciais de qualidade e o acesso a medicamentos e vacinas essenciais seguros, eficazes, de qualidade e a preços acessíveis para todos

3.9 até 2030, reduzir substancialmente o número de mortes e doenças por produtos químicos perigosos e por contaminação e poluição do ar, da água e do solo

3.a fortalecer a implementação da Convenção-Quadro para o Controle do Tabaco da Organização Mundial de Saúde em todos os países, conforme apropriado

3.b apoiar a pesquisa e o desenvolvimento de vacinas e medicamentos para as doenças transmissíveis e não transmissíveis, que afetam principalmente os países em desenvolvimento, proporcionar o acesso a medicamentos e vacinas essenciais a preços acessíveis, de acordo com a Declaração de Doha sobre o Acordo TRIPS e Saúde Pública, que afirma o direito dos países em desenvolvimento de utilizarem plenamente as disposições do Acordo sobre os Aspectos dos Direitos de Propriedade Intelectual Relacionados ao Comércio (TRIPS, na sigla em inglês) sobre flexibilidades para proteger a saúde pública e, em particular, proporcionar o acesso a medicamentos para todos

3.c aumentar substancialmente o financiamento da saúde e o recrutamento, desenvolvimento, treinamento e retenção do pessoal de saúde nos países em desenvolvimento, especialmente nos países de menor desenvolvimento relativo e nos pequenos Estados insulares em desenvolvimento 3.d reforçar a capacidade de todos os países, particularmente os países em desenvolvimento, para o alerta precoce, redução de riscos e gerenciamento de riscos nacionais e globais à saúde.

A partir da análise do objetivo e das metas propostas, reconhecemos a crucial importância de todas as questões elencadas e da necessidade de medidas urgentes que promovam a erradicação de tais problemas. Porém, observamos limitações nas estratégias adotadas para que as metas se consolidem.

Cabe primeiramente destacar que, embora a causalidade das enfermidades previstas no documento não tenha sido explicitada, as estratégias de ação revelam a compreensão reducionista da doença, ao não mencionar outras formas de combate que reconheçam a pluralidade e pressuponham um diálogo entre saberes. Na Agenda 2030, as estratégias de ação partem da compreensão da doença como um estado decorrente da influência ou atuação de agentes externos ao sujeito, como expresso na meta 3.3, que trata do combate às "epidemias de AIDS, tuberculose, malária e doenças tropicais negligenciadas, e combater a hepatite, doenças transmitidas pela água [...]”.

Outras metas reforçam esta percepção, a meta 3.5 , por exemplo, trata dos males decorrentes do uso abusivo de substâncias, incluindo drogas entorpecentes e uso nocivo do álcool; a meta 3.9 atribui mortes e doenças à suscetibilidade a "produtos químicos perigosos" e a condições ambientais, quando sugere riscos por "contaminação e poluição do ar, da água e do solo". Além destas, destacamos a meta 3.6, que busca reduzir as mortes e ferimentos por acidentes em estradas.

Nota-se que todas as metas citadas sugerem fatores estritamente biológicos, químicos ou físicos, descartando, nesse sentido, fatores de outras ordens ou associados à multidimensionalidade humana. Sob esta perspectiva, as estratégias de ação gravitam em torno da pesquisa, do desenvolvimento e do acesso a vacinas e medicamentos, conforme observamos nas metas acima grifadas.

Essa afirmação é reforçada ao analisarmos os Documentos Temáticos, elaborados pela ONU Brasil e apresentados em 2017, com o objetivo de trazer uma revisão preliminar dos $\operatorname{ODS}$ 1, 2, 3, 5, 9 e 143. Especificamente no Objetivo 3, 
nosso foco de análise, admite-se a necessidade de "uma abordagem conjunta de natureza multissetorial dos determinantes da saúde para produzir mais saúde, bem-estar e qualidade de vida para os/as brasileiros/as" (ONU BR, 2017: 47). No entanto, não há no documento nenhuma alusão a possíveis contribuições decorrentes de uma pluralidade de saberes, prevalecendo uma visão centrada no modelo hegemônico de atenção à saúde. Observa-se que o documento menciona o Programa Mais Médicos (PMM), informando, dentre outros dados, que este programa levou à provisão de médicos em todos os Distritos Sanitários Especiais Indígenas (DSEIs). O PMM, que reconhecidamente tem contribuído para a redução das desigualdades em saúde (SANTOS; COSTA; GIRARDI, 2015), não prevê, de forma explícita, uma abertura epistêmica para outras concepções de saúde e doença 4 .

Com o avanço da medicalização, fenômeno considerado uma das principais características do modelo biomédico (MENÉNDEZ, 2005), admite-se uma única concepção de doença, excluindo-se assim uma vasta gama de possibilidades na busca pela promoção de saúde e bem-estar das pessoas. Nesse sentido, é reforçada a concepção do ser humano como máquina artificial, desconsiderando-se suas multidimensionalidades: biológica, psíquica, social, afetiva e racional (MORIN, 2011: 35).

Reduzidos a um fenômeno orgânico, o tratamento das doenças, independente da ordem que as originam ou desencadeiam, restringe-se ao uso de medicamentos e à submissão a procedimentos muitas vezes invasivos. O campo da saúde, nesse sentido, torna-se, acima de tudo, um possível e rentável nicho de mercado. A medicalização, por sua vez, contempla os interesses capitalistas, garantindo sua manutenção e expansão. Como observado por Leff (2015: 310), "a capitalização da medicina orientou o tratamento da saúde mais para a cura da enfermidade do que para prevenção, chegando a perverter a ética médica”.

A busca pela rápida amenização dos males e sofrimentos, aliada à banalização do uso de medicamentos, muitas vezes indicados ou prescritos por profissionais de saúde, desencadearam um grave problema de saúde pública. Frente ao crescente índice de mortes decorrentes do uso indiscriminado de medicamentos, a Organização Mundial da Saúde (OMS) elaborou diretrizes a fim de reduzir as mortes pela superdosagem, principalmente de substâncias opiáceas - como a morfina, heroína ou analgésicos como a oxicodona, responsáveis, segundo estatísticas, pela morte de aproximadamente 70 mil pessoas por ano5.

O caráter comercial empresarial da medicalização, que teve considerável absorção no meio médico brasileiro nas duas últimas décadas, transformou a medicina em negócio, a saúde em produto e a doença em um elemento de potencial lucratividade. Compartilhando desta reflexão, Martin (2004: 35) complementa: "a promessa de saúde é uma isca boa para atrair clientes, mas o que rende mesmo é a doença”.

Embora impactante, a observação de Martin se torna ainda mais plausível ao analisarmos as estatísticas relativas à potencialidade de expansão do mercado farmacêutico no Brasil. Conforme dados do Conselho Federal de Farmácia (CFF), em 2016, o Brasil possuía mais de 70.00o farmácias e ocupava a sexta posição entre líderes de consumo no mercado mundial com projeção de alcançar, em 2018, a quarta posição no ranking, segundo o IMS Health.

\footnotetext{
${ }_{4}$ No site do Ministério da Saúde, é possível encontrar informações sobre o Programa Mais Médicos e seus eixos estruturantes: http://maismedicos.gov.br/

5Disponível em <https://nacoesunidas.org/quase-70-mil-pessoas-morrem-todos-os-anos-por-overdose-de-medicamentos-com-opiaceos-diz-oms/>. Acesso em 22/04/2018.
} 
De acordo com a reportagem disponível no site do Conselho Federal de Farmácia, o aumento da expectativa de vida da população brasileira seria um dos fatores propulsores da demanda por medicamentos e consequente expansão do mercado farmacêutico. Segundo o site, nem a crise político-econômica vivenciada em nosso país é considerada um entrave, pois "não há crise capaz de frear o crescimento do varejo farmacêutico, impulsionado por uma demanda natural"6.

Estes dados colaboram para a compreensão da importância das outras multidimensões apontadas por Morin (2011) que transcendem a visão biologista prevalecente nos documentos.

Paralelo à Agenda 2030 e aos ODS, outros documentos, elaborados inclusive pela mesma instituição (OMS), reconhecem a importância da pluralidade das concepções e práticas médicas e de suas possíveis contribuições na prestação de serviços de saúde e na prevenção de enfermidades. À exemplo citamos o documento intitulado "Estrategia de la OMS sobre medicina tradicional", plano de ação vigente de 2002 a 2004, posteriormente atualizado e relançado para implementação de 2014 a 2023. De acordo com dados da Organização Pan-Americana de Saúde (OPAS), o documento tem por objetivos principais: "prestar apoio aos Estados Membros para que aproveitem a possível contribuição da Medicina Tradicional e Complementar (MTC) a saúde, bem-estar e a atenção centrada nas pessoas, e promover a utilização segura e eficaz da MTC mediante a regulamentação de produtos, práticas e profissionais"

Além de considerações sobre MTC, constam no documento estratégias para inclusão "destas outras medicinas" nos sistemas de saúde dos Estados membros. Reconhecidas como "una parte importante y con frecuencia subestimada de la atención de salud", a MTC adotada como estratégia "será de utilidad para los países que desean desarrollar políticas dinámicas relativas a esta parte importante, y con frecuencia vigorosa y expansiva, de la atención de salud”.

Cabe esclarecer que não se trata de pormenorizar as contribuições do modelo biomédico. Pretendem-se, porém, questionar a invisibilização de outras práticas em um documento que, além de se comprometer a "promover a compreensão intercultural, a tolerância, o respeito mútuo e uma ética de cidadania global e de responsabilidade compartilhada", reconhece "que todas as culturas e civilizações podem contribuir para o desenvolvimento sustentável, constituindo-se como elementos cruciais para tanto".

\section{É uma Agenda do povo, pelo povo e para o povo: que povo?}

O compromisso firmado e reafirmado no decorrer dos ODS de "não deixar ninguém para trás" parece representar a essência deste documento, elaborado a partir da análise dos alcances e estagnações dos ODM, como já citado anteriormente. Para avançar nesse sentido, se propõe a adotar "medidas ousadas" desdobradas nos objetivos e metas aplicáveis para todos os países, independentemente do nível de desenvolvimento.

Estamos trilhando juntos o caminho rumo ao desenvolvimento sustentável, dedicando-nos coletivamente à busca do desenvolvimento global e da cooperação com benefícios mútuos, que podem trazer enormes ganhos para todos os países e todas as partes do mundo. (NAÇÕES UNIDAS, 2015) 
Entretanto, no Objetivo 3, nosso foco de análise, essa pretensa "prosperidade compartilhada", se torna impossível, ou no mínimo improvável considerando-se que as "medidas ousadas" foram construídas sobre as mesmas concepções alinhadas ao paradigma dominante e a um modelo hegemônico de desenvolvimento tendencioso. Essas reflexões nos levam a compreender por que o conceito "desenvolvimento" tem sido veementemente criticado.

Refletindo sobre o poder do desenvolvimento enquanto ideologia ou utopia, compartilhamos da ideia de Montibeller Filho (2001: 52-53) para o qual a implícita ideia de melhoria e de progresso faz com que o desenvolvimento seja uma noção "universalmente desejada". Sustentável, por sua vez, "é mais um rótulo ou adjetivo afixado ao conceito tradicional - desenvolvimento -, e que o deixa, do mesmo modo polissêmico. Mas é esta característica da polissemia que o mantém universalmente aceito”. O conceito desenvolvimento sustentável, definido no Relatório Brundtland em 1987, buscou conciliar as políticas de desenvolvimento e de meio ambiente, o que vem sendo denunciado por ambientalistas como uma estratégia de manter o crescimento econômico e os padrões de consumo das sociedades capitalistas (GÓMEZ-BAGGETHUN, 2019).

De acordo com Stavenhagen (1985), a noção de desenvolvimento resulta de referenciais e critérios específicos elaborados e estabelecidos intencionalmente na manutenção das desigualdades entre regiões e nações. O autor refere-se ainda à teoria da dependência, a partir da qual o subdesenvolvimento não é sinônimo de atraso e sim de dependência e exploração. Já para Xaba (2005: 380), o desenvolvimento está diretamente associado à noção de civilização moderna. Em decorrência, "tem sido (e continua a ser) um ponto de discórdia", assumindo formas diversas "colonialismo ou imperialismo, modernização ou civilização, desenvolvimento ou subdesenvolvimento ou desenvolvimento dependente, até globalização".

Na perspectiva de Bassey (2019: 3), desenvolvimento é uma ideia manipulada, essencialmente imperialista, que categoriza nações em desenvolvidas e subdesenvolvidas. Complementa observando que o termo desenvolvimento sugere "growth, expansion, enlargement, and spread", contudo "none of which captures the sense of justice or equity, or considers the ecological limits of a finite planet”. Também em uma perspectiva crítica, Shiva (2019) afirma que o discurso do desenvolvimento, pautado no sistema capitalista patriarcal, caracteriza-se pela separação entre seres humanos e natureza, e entre os próprios seres humanos, com base em gênero, casta, classe e religião. Estas separações, segundo a autora, são produtoras de violências.

Estas abordagens estão alinhadas com as críticas de Escobar (2007), que concebe a noção de desenvolvimento como eurocêntrica e tecnocrática e, portanto, incapaz de ser aplicada no sul do globo sem sua análise e reformulação sob a ótica e a partir das realidades locais. A crítica latino-americana ao conceito hegemônico de desenvolvimento tem vislumbrado outros cenários político-epistêmicos, destacando conceitos como bien vivir, bens comuns, direitos da natureza, ética do cuidado, soberania alimentar, autonomia, ontologias relacionais, entre outros (SVAMPA, 2019).

Como superar a pobreza extrema, a violência, a fome, a doença e de todas as outras mazelas listadas nos ODS utilizando-se das mesmas bases que colocaram povos e populações na condição de subalternidade em que se encontram? 


\section{Intermedicalidade: os caminhos alternativos no diálogo entre saberes}

De acordo com Leff (2015: 311), "o desenvolvimento sustentável colocou o ser humano no centro de seus objetivos, propondo entre suas metas a qualidade de vida e o desenvolvimento integral de suas potencialidades". Porém, a garantia de uma vida plena e saudável não se resume em ampliar a cobertura dos serviços básicos de saúde oferecidos, pois "implica a necessidade de reconceitualizar a saúde e a doença, de reorientar os serviços de saúde pública e as práticas médicas em novas formas de desenvolvimento" (LEFF, 2015: 312).

Bezerra (2017: 1045) destaca a importância de "romper com visões fragmentadas de problemáticas relacionadas a distintos campos do saber para estabelecer relações entre o ambiente, a saúde e o território". As transformações tanto nos ambientes quanto na sociedade promovida pela globalização, segundo o mesmo autor, "merecem um esforço de investigação que avance sobre o paradigma cartesiano positivista mediante investigações cada vez mais interdisciplinares".

Aliado a este debate acerca da pluralidade de saberes e da possibilidade de recriar conhecimentos a partir de uma relação dialética, agregamos o conceito de intermedicalidade. A intermedicalidade pressupõe o reconhecimento e a articulação dos saberes e práticas provenientes de diferentes perspectivas socioculturais na produção de medicinas híbridas, formando um conjunto criativo e dinâmico (GREENE, 1998; FÓLLER, 2004). Cabe destacar que a viabilidade deste processo pressupõe uma zona de contato e o estabelecimento da chamada interculturalidade.

Zona de contato, conceito sugerido por Mary Louise Pratt, professora de literatura latino-americana e literatura comparada na Universidade de Stanford e autora do livro Imperial Eyes. Travel Writing and Transculturation?, seria o espaço de encontros coloniais em que são estabelecidas relações que comumente retratam desigualdades e são permeadas por conflitos. Com este conceito, Pratt (1999: 12) propõe "uma ótica que tira a comunidade (e a identidade, seu corolário) do centro para examinar a maneira como os laços sociais vão se fazendo por entre linhas de diferença, de hierarquia e de pressupostos conflituosos ou não compartilhados". E complementa:

\footnotetext{
Tal abordagem consideraria o modo como as diferenças e as hierarquias são produzidas no contato e pelo contato dessas linhas umas com as outras. Diferenças de classe, etnia e gênero seriam então analisadas não em termos do pertencimento das pessoas a comunidades particulares, mas em termos da produção e da reprodução dessas mesmas diferenças no contato socialmente estruturado entre grupos que vem sendo forçosamente aglutinados em sua irremediável separação. Tal 'perspectiva do contato' assumiria a heterogeneidade de um grupo social e poria em primeiro plano a relacionalidade do sentido. (PRATT, 1999: 12)
}

Este conceito, portanto, promove a visibilidade das populações marginalizadas e subalternas, destinadas a esta condição pela unilateralidade da história que privilegia a versão do colonizador e legitima o processo de dominação dos povos e espoliação de suas riquezas materiais e imateriais. Compartilhando dessa ideia, Giorgia (2017: 294) destaca que "a invisibilidade das populações marginalizadas transforma-se em copresença social e histórica”. 
O outro conceito elencado como base na compreensão da intermedicalidade é o conceito da interculturalidade. De forma genérica a noção de interculturalidade remete a um espaço imparcial de encontro em que diversas culturas devem empreender esforços para uma convivência harmônica. Porém, conforme alerta Boccara (2015: 202-203), este é o discurso comumente utilizado pelos agentes do Estado que "piensan la interculturalidad como un espacio neutro y casi encantado de la comunicación sin fronteras entre culturas”. Essa concepção de interculturalidade "tiende a desvincular los problemas culturales de los procesos socio-históricos de dominación social, explotación económica y sujeción política” (BOCCARA, 2015: 201).

Convergindo com essa percepção, Leau (2017: 36) discute as diferenças entre a "interculturalidade normativa" e a "interculturalidade de fato":

\begin{abstract}
La primera alude a la interculturalidad como un proyecto político o ético que suele suponer -explícitamente o no- un cambio social para lograr un diálogo más equitativo y crítico entre personas de distintas culturas. La segunda, que se denomina también descriptiva, corresponde a las influencias mutuas que se han dado históricamente entre diferentes culturas, siendo buscadas o no.
\end{abstract}

Aprofundando-se a análise, é possível perceber que a interculturalidade consiste em uma importante ferramenta social e política capaz de contribuir com processo de descolonização tanto material quanto simbólica.

\begin{abstract}
la interculturalidad se ha transformado en una categoría muy extensa que engloba una cantidad creciente de fenómenos de distintas índoles [...] Alude tanto a un espacio concreto de encuentro entre dos culturas como al asentamiento de mecanismos sociales que buscan facilitar la comunicación entre grupos culturalmente diferentes. Remite a fenómenos de orden tanto simbólico como material. [...] Aparece tanto como un producto lógico y espontáneo de la historia de las relaciones inter-étnicas como el resultado esperado de la política voluntarista del Estado. (BOCCARA, 2015: 208)
\end{abstract}

Com base na discussão, entende-se que, longe de um espaço de suposta neutralidade, a interculturalidade, embora constituindo importante elemento na luta pela justiça social, depende na prática, dos interesses vinculados aos grupos que dela se utilizam. Nesse sentido, podem servir tanto como instrumento de dominação e controle, como auxiliar na comunicação e no empoderamento das minorias sociais. Ferreira (2015) atenta que a interculturalidade é uma categoria polissêmica, utilizada de forma múltipla e imprecisa. Neste sentido, sua importância pode residir em uma perspectiva prescritiva, apontado por Candau (2008), como um projeto de transformação social voltado para o respeito às diferenças e à construção de relações mais simétricas e dialógicas (FERREIRA, 2015).

A intermedicalidade e sua viabilização na prática supõe a superação da distinção entre o conhecimento técnico e não técnico, especializado e leigo, mais uma estratégia para legitimar o exclusivismo epistemológico da ciência e desqualificar ou descartar os conhecimentos tradicionalmente construídos.

\footnotetext{
A fronteira entre os dois tipos de conhecimento é complexa e fluida e a imposição de sua separação como imperativo de rigor, de eficácia ou de racionalidade, particularmente em circunstâncias em que estão em causa problemas complexos e diagnósticos controversos destes, torna legítima a suspeita de ela estar ao serviço de um projeto específico de organização do saber e do poder, mesmo quando legitimado por preocupações com o bem comum (SANTOS, 2005: 55).
}

Corroborando com este debate, Langdon observa que a dificuldade de comunicação entre conhecimento científico e "tradicional" decorre do grau intercultural e de um preconceito implícito. Ressalta que embora o leigo não possua a formação profissional em saúde, "ele também tem seu sistema médico, seu mundo 
de conhecimentos, e sua maneira de diagnosticar e interpretar as doenças e suas causas" (BECKER, 2009: 3).

Sem serem suplantadas pela biomedicina, outras formas de conhecimento florescem na América Latina, como também em outras partes do mundo (LANGDON, 2014: 1027). Seja pela insatisfação com as práticas biomédicas, impessoais e invasivas, ou pelo fácil acesso e baixo custo, tem crescido em todo o mundo a procura por essas práticas que se fundamentam em saberes diversos, pressionando estratégias e ações em prol da legitimação dessas medicinas "outras”. No Brasil, a implementação do Subsistema de Atenção à Saúde Indígena (SASI), por meio da Lei 9.836/99, a Política Nacional de Práticas Integrativas e Complementares (PNPIC), aprovada pela Portaria 971 de 3 de maio de 2006 e a Política Nacional de Plantas Medicinais e Fitoterápicos (PICs), regulamentada pelo Decreto 5.813, de 22 de junho de 2006, são exemplos do reconhecimento da coexistência dos saberes plurais.

Porém, conforme observa Langdon (2017: 459), "existe una brecha entre la garantía jurídico-política de un derecho y sus resultados en la vida cotidiana de los ciudadanos". Em se tratando da política de atenção à saúde indígena, a autora destaca que, embora elaborada com base nos princípios de acesso universal, participação comunitária e articulação de saberes, na prática está "marcada por un alto grado de estandarización de rígidas normas técnicas prescriptivas, cuyo carácter estrictamente biomédico las hace impermeables a contextos y singularidades locales" (LANGDON, 2017: 461).

Pesquisas etnográficas que promoveram a interface entre três campos disciplinares (antropologia, saúde coletiva e ciências farmacêuticas), apontam que os problemas estão centrados, principalmente, no despreparo de gestores e profissionais de saúde para atuarem em realidades marcadas pelo preconceito em que a "práxis é caracterizada por uma forte institucionalização, centralização e burocracia, sob a hegemonia do modelo biomédico" (LANGDON; GRISOTTI, 2016: 100).

Assim, a intermedicalidade surge como um caminho possível. Porém, dada sua complexidade e os mecanismos de controle e de poder que atuam pela manutenção do status quo, consiste ainda um grande desafio viabilizá-la "de fato" (LEAU, 2017).

\section{Considerações finais}

Estes modos biomédicos de compreender e intervir nos corpos possuem estatuto hegemônico devido à adoção de seus ideais - caracterizados como modernos - por classes dominantes (XABA, 2005), e que também encontram aceitação ampla e legitimidade na população de forma geral (McCALLUM; ROHDEN; GRUDZINSKI, 2015: 08). Esta hegemonia, no entanto, não se estabelece livre de contestações e, com a emergência de discursos favoráveis à diversidade cultural, tem-se buscado formas "que permitam a presença de tradições paralelas no pensar e tratar do corpo e dos seus males e processos fisiológicos e mentais" (McCALLUM; ROHDEN; GRUDZINSKI, 2015: 08). Deste modo, esta hegemonia biomédica está no centro de práticas e saberes divergentes, sem estabelecer um controle absoluto sobre estas "outras" medicinas.

A lógica prática da biomedicina age mais como uma âncora poderosa, ou melhor, uma série de âncoras, um controle disperso sobre os modos de vivenciar e de agir sobre os processos corporais. Suas formas e modos de operação compõem um ponto de referência que exerce uma força de gravidade constante, tornando-se o pivô no centro de um turbilhão de práticas e lógicas outras, paralelas, alternativas (e assim por diante) 
que são fincadas socialmente e produzidas a partir de distintas histórias e culturas. (McCALLUM; ROHDEN; GRUDZINSKI, 2015: 8)

São inegáveis as contribuições proporcionadas pelos avanços científicos e tecnológicos. Contudo, a apropriação desses importantes elementos pelo modelo de desenvolvimento vigente, que busca expandir seus domínios e influência, tem contribuído para a manutenção das desigualdades evidenciadas nas classificações dos países do mundo em desenvolvido, subdesenvolvidos e em desenvolvimento, Primeiro Mundo e Terceiro Mundo, Norte e Sul, entre outras.

Compreender estes complexos processos implica a ressignificação dos conceitos de saúde e doença e na percepção do ser humano em suas multidimensionalidades. Portanto, avançar no sentido de promover efetivamente a saúde e o bem-estar das pessoas pressupõe combater a hierarquização entre saberes e a instauração de uma relação dialética entre as diferentes formas de viver, perceber, significar e atuar no mundo.

Recebido em 31 de agosto de 2019.

Aprovado em 8 de fevereiro de 2020.

\section{Referências}

BARROS, José Augusto de. Pensando o processo saúde doença: a que responde o modelo biomédico? Saúde e Sociedade. São Paulo, 11 (1): 67-84, 2002.

BASSEY, Nnimmo. "Breaking the chains of development". In: KOUTHARI, Ashish et al. (eds.). Pluriverse: a post-development dictionary. Delhi: Tulika Books, 2019. pp. 3-5.

BATISTELLA, Carlos. "Saúde, Doença e Cuidado: complexidade teórica e necessidade histórica”. In: FONSECA, A. F.; CORBO, A. M. D'A. (orgs.). O território e o processo saúde-doença. Rio de Janeiro: EPSJV/FIOCRUZ, 2007. pp. 25-50.

BAUMAN, Zygmunt. O mal-estar da pós-modernidade. Rio de Janeiro: Jorge Zahar, 1988.

BECKER, Sandra Greice et al. Dialogando sobre o processo saúde/doença com a Antropologia: entrevista com Esther Jean Langdon. Revista Brasileira de Enfermagem 62 (2): 323-326, 2009.

BEZERRA, Anselmo César Vasconcelos. Vigilância ambiental em saúde no Brasil: heranças e desafios. Saúde e Sociedade 26 (4): 1044-1057, 2017.

BOCCARA, Guillaume. "Saúde indígena: políticas comparadas na América Latina”. In: LANGDON, Esther Jean; CARDOSO, Marina D. (orgs). Saúde indígena: políticas comparadas na América Latina. Florianópolis: Ed. da UFSC, 2015. pp. 195-216.

BOFF, Leonardo. Saber cuidar. Rio de Janeiro: Vozes, 2014. 
CANDAU, Vera Maria. Direitos humanos, educação e interculturalidade: as tensões entre igualdade e diferença. Revista Brasileira de Educação, 13 (37): 45-56, 2008.

CAPRA, Fritjof. O ponto de mutação. São Paulo, Cultrix, 1982.

CHAKRABARTY, Dipesh. Provincializing Europe: postcolonial thought and historical difference. Princeton, New Jersey: Princeton University Press, 2000.

CUNHA, Manuela Carneiro da. "Relações e dissensões entre saberes tradicionais e saber científico". In: Cultura com Aspas e outros ensaios. São Paulo: Cosac Nayf, 2009. pp. 301-310.

ESCOBAR, Arturo. "Post-development as a concept and social practice". In: ZIAI, A. (ed.). Exploring Post-Development: Theory and Practice, Problems and Perspectives. New York: Routledge, 2007. pp. 18-31.

FERREIRA, Luciane Ouriques. "Interculturalidade e saúde indígena no contexto das políticas públicas brasileiras”. In: LANGDON, E. J.; CARDOSO, M. D. (orgs.) Saúde Indígena: Políticas comparadas na América Latina. Florianópolis: Editora da UFSC, 2015. pp. 217-246.

FERTONANI, Hosanna Pattrig et al. Modelo assistencial em saúde: conceitos e desafios para a atenção básica brasileira. Ciência e Saúde Coletiva, 20 (6): 18691878, 2015

FOLLÉR, Maj-Lis. "Intermedicalidade: a zona de contato criada por povos indígenas e profissionais de saúde". In: LANGDON, E. J.; GARNELO, L. (orgs.). Saúde dos povos indígenas: reflexões sobre antropologia participativa. Rio de Janeiro: Contra Capa: Associação Brasileira de Antropologia, 2004. pp. 129-147.

GIORGIA, Piras. Transculturação, intersubjetividade, zona de contato em uma perspectiva decolonial da tradução. CONGRESSO INTERNACIONAL EPISTEMOLOGIAS DO SUL, 2016, Foz do Iguaçu - PR. Anais eletrônicos do Congresso Epistemologias do Sul. Foz do Iguaçu: UNILA, 2017.

GÓMEZ-BAGGETHUN, Erik. "Sustainable development". In: KOUTHARI, Ashish et al. (ed.). Pluriverse: a post-development dictionary. Delhi: Tulika Books, 2019. pp. 71-73.

GREENE, Shane. The shaman's needle: development, shamanic agency, and intermedicality in Aguaruna Lands, Peru. American Ethnologist, 25 (4): 634-658, 1998.

GÜEMES, Alonso Muños. Medicina tradicional en la Huasteca Potosina. Glosario médico español tenek. Ciudad Valles, San Luis Potosí: Fundación Universitaria Andaluza Inca Garcilaso, 2012. Disponível em: <http://www.eumed.net/libros-gratis/2013/1284/index.htm> Acesso em: dez. 2017.

IGREJA, Paula Sofia da. Performance Clown e saúde: o papel dos trapamédicos na humanização do ambiente hospitalar na cidade de Blumenau. Dissertação de (Mestrado em Desenvolvimento Regional), Universidade Regional de Blumenau, 2016.

LANGDON, Esther Jean. Os diálogos da antropologia com a saúde: contribuições para as políticas públicas. Salud Colectiva, 13 (3): 457-470, 2017. 
LANGDON, Esther Jean; GARNELO, Luiza. Articulación entre servicios de salud y "medicina indígena": reflexiones antropológicas sobre política y realidad en Brasil. Ciência \& Saúde Coletiva, 19 (4): 1019-1029, 2014.

LANGDON, Esther Jean; GRISOTTI, Márcia. Políticas públicas: reflexões antropológicas. Florianópolis: Ed. da UFSC, 2016.

LANGDON, Esther Jean; WIIK, Flávio Braune. Antropologia, saúde e doença: uma introdução ao conceito de cultura aplicado às ciências da saúde. Revista Latino-Americana de Enfermagem, 18 (3): 1-9, 2010.

LEAU, Carmen Yon. La interculturalidad realmente existente en salud. Revista Argumentos, 11 (3): 36-41, 2017.

LEFF, Enrique. Saber Ambiental: sustentabilidade, racionalidade, complexidade, poder. Rio de Janeiro: Vozes, 2015.

MACHADO, Maria Helena Pereira Toledo. Resenha: PRATT, Mary Louise. Os Olhos do Império. Relatos de viagem e transculturação. Universidade de São Paulo. Revista Brasileira de História, 20 (39): 281-289, 2000.

MARTIN, Leonard M. A ética e a humanização hospitalar. In: PESSINI, Leo; BERTACINI, Luciana (orgs.). Humanização e Cuidados Paliativos. 2. ed. São Paulo: Edições Loyola, 2004. pp. 31-49.

MARTINS, Paulo Henrique. O ensaio sobre o dom de Marcel Mauss: um texto pioneiro da crítica decolonial. Sociologias, 16 (36): 22-41, 2014.

McCALLUM, Cecília; ROHDEN, Fabíola; GRUDZINSKI, Roberta. "Introdução Hegemonia biomédica e pluralismo ontológico no Brasil". In: McCALLUM, C.; ROHDEN, F. (org.). Corpo e saúde na mira da antropologia: ontologias, práticas, traduções. Salvador: EDUFBA/ABA, 2015. pp. 7-26.

MENENDÉZ, Eduardo. El Modelo Médico y la Salud de los Trabajadores. Salud Colectiva, 1 (1): 9-32, 2005.

MONTIBELLER-FILHO, Gilberto. O mito do desenvolvimento sustentável: Meio ambiente e custos sociais no moderno sistema produtor de mercadorias. Florianópolis: Ed. da UFSC, 2001.

MORIN, Edgar. Os sete saberes necessários à educação do futuro. São Paulo: Cortez, Brasília: UNESCO, 2011.

MORIN, Edgar. Saberes Globais e Saberes Locais. Rio de Janeiro: Garamond, 2010.

MORIN, Edgar. Terra-pátria. Lisboa: Instituto Piaget, 1993.

NAÇÕES UNIDAS NO BRASIL - ONU BR. A Agenda 203o. Disponível em: < https://nacoesunidas.org/pos2015/agenda2030/ > Acesso em: jul. 2019.

ORGANIZACIÓN MUNDIAL DE LA SALUD. Estrategia de la OMS sobre medicina tradicional 2014-2023. Disponível em: <https://www.who.int/topics/traditional_medicine/WHO-strategy/es/>. Acesso em: ago. 2019.

PRATT, Mary Louise. A crítica na zona de contato: nação e comunidade fora de foco. Travessia: Revista de literatura, 38: 7-30, 1999.

QUIJANO, Anibal. Colonialidade do poder, eurocentrismo e América Latina. Buenos Aires: CLACSO, 2005. 
SANTOS, Boaventura de Sousa (org). Semear outras soluções: os caminhos da biodiversidade e dos conhecimentos rivais. Rio de Janeiro: Civilização Brasileira, 2005 .

SANTOS, Boaventura de Sousa; MENESES, Maria Paula G. de. NUNES, João Arriscado. "Para ampliar o cânone da ciência: a diversidade epistemológica do mundo". In: SANTOS, Boaventura de Sousa (org). Semear outras soluções:os caminhos da biodiversidade e dos conhecimentos rivais. Rio de Janeiro: Civilização Brasileira, 2005. pp. 21-26.

SANTOS, Leonor Maria Pacheco; COSTA, Ana Maria; GIRARDI, Sábado Nicolau. Programa Mais Médicos: uma ação efetiva para reduzir iniquidades em saúde. Ciência e Saúde Coletiva, 20 (11): 3547-3552, 2015.

SCLIAR, Moacyr. Do mágico ao social: trajetória da saúde pública. São Paulo: SENAC, 2005.

SHIVA, Vandana. "Development - for the 1 per cent". In: KOUTHARI, Ashish et al. (eds.). Pluriverse: a post-development dictionary. Delhi: Tulika Books, 2019. pp. 6-8.

STAVENHAGEN, Rodolfo. Etnodesenvolvimento: uma dimensão ignorada no pensamento desenvolvimentista. Anuário Antropológico, 84: 11-44, 1985.

SVAMPA, Maristella. The Latin American critique of development. In: KOUTHARI, Ashish et al. (eds.) Pluriverse: a post-development dictionary. Delhi: Tulika Books, 2019. pp. 18-21.

TAMBELLINI, Anamaria Testa. CÂMARA, Volney de Magalhães. A temática saúde e ambiente no processo de desenvolvimento do campo da saúde coletiva: aspectos históricos, conceituais e metodológicos. Ciência \& Saúde Coletiva, 3 (2): 47-59, 1998.

VIOTTI, Ana Carolina de Carvalho. As práticas e os saberes médicos no Brasil colonial (1677-1808). Dissertação (Mestrado em História), Faculdade de Ciências Humanas e Sociais, Universidade Estadual Paulista, 2012.

XABA, Thokozani. "Prática médica marginalizada: a marginalização e transformação das medicinas indígenas na África do Sul”. In: SANTOS, B. S. (org.). Semear outras soluções: os caminhos da biodiversidade e dos conhecimentos rivais. Rio de Janeiro: Civilização Brasileira, 2005. pp. 377-421. 